\title{
Significação e argumentação ${ }^{1}$
}

\author{
Signification et argumentation
}

\section{Marion Carel}

Escola de Altos Estudos em Ciências Sociais (EHESS) - Paris - França

\begin{abstract}
Resumo: Neste artigo, eu me proponho a voltar sobre a questão muito geral da significação das palavras. Que valores efetivamente uma língua associa às palavras e para que servem esses valores na determinação do sentido dos nossos discursos? A resposta atualmente banal é que as palavras descrevem o mundo e que suas significações, sistematicamente expressas, se acrescentam, umas após as outras, para determinar o sentido dos nossos discursos. É essa resposta banal que discutirei. Apoiando-me nos trabalhos de Anscombre e Ducrot, defenderei a hipótese de que a significação das palavras é, não informativa, mas argumentativa. Não quero dizer com isso que falar consiste em um esforço para persuadir. Falar não consiste mais em persuadir do que em descrever o mundo. O que eu afirmo é que falar consiste em construir um texto, em entrelaçar as palavras, em colocá-las em relação, ou, ainda, em apresentá-las como se generalizando ou se exemplificando, ou em opô-las. Falar consiste em construir um texto que, ao entrar num diálogo, ao mesmo tempo, fará eco ao discurso de outro e tornará obrigatória sua resposta. Este artigo constituirá uma apresentação renovada do que eu chamei, de maneira um pouco pomposa, a Teoria dos Blocos Semânticos.
\end{abstract}

Palavras-chave: Significação; Argumentação; Teoria dos Blocos Semânticos.

Résumé: Je me propose dans cet article de revenir sur la question très générale de la signification des mots. Quelles valeurs en effet une langue associe-t-elle aux mots et à quoi servent ces valeurs dans la détermination du sens de nos discours ? La réponse actuellement banale est que les mots décrivent le monde et que leurs significations, systématiquement exprimées, s'ajoutent, brique après brique, pour déterminer le sens de nos discours. C'est cette réponse banale que je vais discuter. M'appuyant sur les travaux d'Anscombre et Ducrot, je défendrai l'hypothèse que la signification des mots est, non pas informative, mais argumentative. Je ne veux pas dire par là que parler consiste en un effort pour persuader. Parler ne consiste pas plus à persuader qu'à décrire le monde. Ce que je défends, c'est que parler consiste à construire un texte, à entrelacer les mots, à les mettre en regard, ou encore à les présenter comme se généralisant ou s'exemplifiant, à les opposer. Parler consiste à construire un texte qui, entrant dans une conversation, à la fois fera écho au discours de l'autre et contraindra sa réponse. Cet article constituera une présentation rénovée de ce que j'ai appelé, de manière un peu pompeuse, la Théorie des Blocs Sémantiques.

Mots-clés: Signification; Argumentation ; Théorie des Blocs Sémantiques.

\footnotetext{
${ }^{1}$ Tradução de Cristiane Dall Cortivo-Lebler (Unisc). Revisão da tradução de Leci Borges Barbisan (PUCRS).
} 


\section{Introdução}

Neste artigo, eu me proponho a voltar sobre a questão muito geral da significação das palavras. Que valores efetivamente uma língua associa às palavras e para que servem esses valores na determinação do sentido dos nossos discursos? A resposta atualmente banal é que as palavras descrevem o mundo e que suas significações, sistematicamente expressas, se acrescentam, umas após as outras, para determinar o sentido dos nossos discursos. É essa resposta banal que discutirei. Apoiando-me nos trabalhos de Anscombre e Ducrot, defenderei a hipótese de que a significação das palavras é, não informativa, mas argumentativa. Não quero dizer com isso que falar consiste em um esforço para persuadir. Falar não consiste mais em persuadir do que em descrever o mundo. $O$ que eu afirmo é que falar consiste em construir um texto, em entrelaçar as palavras, em colocá-las em relação, ou, ainda, em apresentá-las como se generalizando ou se exemplificando, ou em opô-las. Falar consiste em construir um texto que, ao entrar num diálogo, ao mesmo tempo, fará eco ao discurso de outro e tornará obrigatória sua resposta. É uma atividade em si, a de falar, de construir um discurso, de responder a outro discurso e, assim, eu assumirei, aplicando aos enunciados, a frase de Maurice Denis a respeito dos quadros:

"Lembrar-se de que um quadro, antes de ser um cavalo de batalha, uma mulher nua ou uma história qualquer, é essencialmente uma superfície plana, recoberta de cores dispostas em determinada ordem."

Não há, de acordo com o que penso, função informativa primeira em nossos enunciados. Nossos discursos não são senão tramas de palavras "dispostas em determinada ordem", e a significação das palavras é argumentativa no sentido de que é ela que determina essa construção. Ela permite às palavras se entrelaçarem, se generalizarem, se exemplificarem, se oporem. Ela permite ver, em uma simples sequência de palavras, um texto construído. Tal é o papel da significação das palavras ditas lexicais; tal é, igualmente, o papel da sintaxe e das palavras gramaticais. Um texto pode, em função de sua sintaxe ou de suas palavras gramaticais, dizer mais que os próprios termos lexicais, dizer mais e, até mesmo, veremos, dizer algo contrário a suas palavras lexicais. O sentido dos nossos discursos não é puramente composicional. Os textos enriquecem as associações, os entrelaçamentos, as argumentações previstas por suas palavras. Este artigo constituirá uma apresentação renovada do que eu chamei, de maneira um pouco pomposa, a Teoria dos Blocos Semânticos.

\section{A significação das expressões é argumentativa}

Iniciarei retomando a distinção feita por Ducrot entre sentido e significação. Entendemos por "expressão", inicialmente, um termo simples (lobo, ler), um termo complexo (um lobo feroz, ler um artigo) ou uma sequência gramatical (um lobo feroz entrou no tribunal, eu li o seu artigo). Todas as expressões compartilham dessa propriedade de lhes ser atribuído um valor semântico. Chamarei "significação" o valor que a língua associa a uma expressão fora de emprego e "sentido" o valor de um emprego da expressão. Mas o que se entende exatamente por "expressão fora de emprego"? Existe um laço entre a significação das expressões fora de emprego e o sentido dos empregos? Nem todos os linguistas respondem da mesma maneira a essas questões.

Benveniste, como sabemos, distingue dois tipos de significação: a significação semiótica e a significação semântica. A significação semiótica corresponde ao que chamei "significação" e diz respeito aos elementos do sistema da língua. Tratase de descrever os signos no interior desse sistema, comparando-os aos outros signos do sistema. O signo sabre será, assim, comparado, independentemente de qualquer emprego, ao signo árvore (arbre), cujo significante é semelhante; da mesma forma, será comparado ao signo espada, cujo significado é semelhante. A essa ordem semiótica se opõe aquilo que Benveniste chama de ordem 
semântica e que diz respeito, por sua vez, aos enunciados. Cada enunciado resulta, segundo Benveniste, de uma apreensão da língua pelo locutor, constituindo-se, para este último, um meio de agir sobre seu interlocutor. Os enunciados dizem respeito ao mundo e seu sentido não deriva, portanto, da significação das expressões que os compõem. A oposição entre significação e sentido reflete, segundo Benveniste, uma oposição entre, de um lado, o valor da expressão no interior do sistema da língua e, de outro lado, o emprego da expressão por um locutor que procura agir sobre seu interlocutor.

Este não é o ponto de vista de Ducrot, que considera, como a maior parte dos linguistas atuais, que a tarefa do linguista é dar conta dos empregos das expressões. Para Ducrot, as expressões fora de emprego são apenas construções teóricas que permitem compreender os empregos da língua. A significação das expressões fora de seu emprego é somente uma ferramenta que permite prever, uma vez conhecido o contexto, o sentido de seus empregos. Nesse quadro, para determinar a significação de sabre, é necessário comparar os empregos desse termo entre eles. Compararemos os exemplos (1) e (2) e inscreveremos, em seguida, o que eles compartilham da significação de sabre:

(1) O pirata empunhou um sabre com o qual se lançou sobre o tenente do Rei.

(2) Seu sabre estava enferrujado há muito tempo, ele deu-o a seu filho de sete anos.

Constituída pelo conteúdo semântico comum aos seus diversos empregos, a significação de sabre permitirá, a posteriori, prever o sentido dos enunciados que são constituídos com tal palavra. Apesar de uma certa simetria na sua definição, os dois tipos de valores que constituem a significação e o sentido têm papéis assimétricos.

É ao modo de Ducrot que entendo as noções de "expressão fora de emprego" e de "significação". A significação é, para mim, constituída por elementos que permitem prever o sentido dos enunciados. Ela intervém, contudo, no cálculo do sentido de todo enunciado que comporta a expressão? É isso que sustentam os defensores do princípio da composicionalidade, para quem todos os empregos de uma palavra têm por função idêntica a de exprimir sua significação. Eu defenderei, ao contrário - essa tese será desenvolvida nas seções 4 e 5 - que, às vezes, as palavras têm uma outra função que não a de exprimir sua significação. A significação prevê o papel de somente alguns dos empregos das palavras. A significação de sabre prevê o sentido de (1) e de (2), mas ela não intervém, segundo o que penso, em (3), onde a palavra sabre poderia bem ser substituída por espadas, calçados para praticar esportes, toalhas, papéis, livros, quer dizer, simplesmente coisas imaginemos que Pedro e João tenham marcado um encontro na sala de esgrima para um combate amistoso:

(3) Pedro entrou na sala de esgrima. Ele se sentou em um banco e colocou sua mochila ao lado de um armário, onde ficavam alguns sabres. Como de costume, Joao estava atrasado.

Objetar-me-ão que, em (3), também o emprego da palavra sabre mobiliza sua significação, pois ela faz referência a objetos dos quais se pode dizer com certeza isto é um sabre. Talvez (ainda que se pudesse tratar de espadas ou de sabres de madeira), mas isso não importa para a interpretação de (3). (3) comunica apenas que Pedro se sentou em um lugar onde permanecem alguns objetos, um lugar de onde partem os jogadores, um lugar de solidão. O verbo ficam informa que o lugar está vazio agora, que a atividade acabou; é graças ao verbo ficar que se compreende que Pedro está à espera; a natureza dos objetos que ficam não tem, por outro lado, nenhuma importância para a interpretação de (3) - nada além do fato de que esses objetos estão em um armário. $A$ significação da palavra sabre não intervém no sentido de (3) e a variação seguinte afirmaria fundamentalmente o mesmo conteúdo - será necessário, evidentemente, voltar a esse "fundamentalmente" (conforme seção 4):

Pedro entrou na sala de esgrima. Ele se sentou em um banco e colocou sua mochila ao lado de 
uma mesa sobre a qual estavam alguns casacos.

Como de costume, João estava atrasado.

Não se trata, para cada palavra lexical de um enunciado, de descrever um pequeno pedaço da realidade. As palavras não são peças de madeira que nossos discursos reuniriam em quebra-cabeças representando o mundo. As palavras lexicais têm papéis variados e a significação de uma palavra permite descrever o papel de apenas alguns de seus empregos.

Mas qual é esse papel? $\mathrm{O}$ que comunica 0 emprego da palavra sabre em (1) e em (2)? O que comunica a significação? Ela dá indicações "informativas" sobre propriedades que teria um objeto do mundo ou ela dá indicações "avaliativas" sobre a maneira pela qual o locutor avalia a situação? Isso parece - e eu insito "parece" - depender das palavras. A significação da palavra sabre parece conter indicações informativas, enquanto a significação de uma palavra como prudente conteria indicações avaliativas (o mesmo comportamento pode ser qualificado como prudência ou como covardia; falar de prudência é escolher avaliar positivamente). Uma originalidade dos trabalhos de Anscombre e Ducrot foi a de mostrar que a significação contém, igualmente, indicações "argumentativas", isto é, indicações a respeito das argumentações às quais a expressão pode servir.

Os primeiros exemplos de Anscombre e Ducrot concerniram às palavras gramaticais, como mas, até mesmo, pouco, um pouco, ou, ainda, quase. Imaginemos, assim, que uma criança, ao voltar da escola de música, anuncia a seus pais:

(4) Quase fui escolhido para tocar no concerto de final de ano.

Admitamos que ser escolhido para o concerto de final de ano seja uma boa notícia. Nesse contexto, (4) é um argumento para uma conclusão como estou contente: podemos, materialmente, fazer seguir a (4) estou contente; ou, em uma ordem sintática inversa, podemos fazer com que estou contente porque seja seguido por (4). Ora, factualmente, (4) significa que a criança não foi escolhida para o concerto de final de ano, o que, em nosso contexto, é uma má notícia. Dito de outro modo, (4) informa a respeito do mesmo fato que o enunciado (5):

(5) Não fui escolhido para tocar no concerto de final de ano.

Mas, enquanto (5) argumentaria para não estou contente, (4) argumenta para estou contente. Ao mesmo tempo que descreve um fato decepcionante, (4) Ihe dá a aparência de uma boa notícia. O advérbio quase impõe ao enunciado (4) uma direção argumentativa contrária àquela que (4) informa. A direção argumentativa de (4) é independente daquilo que é descrito. Ela não é dedutível das informações dadas; ela é adicionada a essas indicações. Isso é verdadeiro para as frases que comportam quase e é igualmente verdadeiro para os termos do léxico. Faz parte da significação própria de procurar que seja normal encontrar. $O$ encadeamento argumentativo (6) está previsto na significação de procurar.

(6) Se tu procurares tuas chaves, tu as encontrarás.

É evidente que alguém que procura possa não encontrar, mas, nesse caso, é um conector adversativo que empregaremos e diremos (7):

(7) Procurei minhas chaves e, no entanto, não as encontrei.

A argumentação está na língua no sentido de que a significação fora de emprego contém diretamente indicações sobre as argumentações que poderão ser desenvolvidas no discurso quando do emprego das palavras.

A Teoria dos Blocos Semânticos radicaliza a posição de Anscombre e Ducrot, sustentando que a significação de uma expressão fora do emprego é constituída unicamente por indicações 
argumentativas. A significação das expressões tem por papel - e por único papel - prever os encadeamentos argumentativos e a palavra sabre, segundo o que penso, não é um termo mais informativo que a palavra prudente. Todo enunciado é parafraseável por encadeamentos que comportam uma conjunção do tipo donc (se, porque, pois,...) ou uma conjunção do tipo pourtant (no entanto, ainda que, mesmo se,...) e a significação das palavras, associada à sintaxe e à estrutura do texto, permite prever essas paráfrases.

\section{Descrição argumentativa de prudente e de sabre}

Mas como descrever argumentativamente a palavra prudente e a palavra sabre? Iniciemos pelo exemplo da palavra prudente, um caso standard da teoria.

Dizer de Pedro que ele foi prudente significa dizer, ao mesmo tempo, que ele se deparou com um perigo e que ele modificou sua atividade. Mas isso não é tudo. Não é suficiente que Pedro tenha encontrado um perigo e que ele tenha modificado sua atividade para que qualifiquemos como prudente 0 seu comportamento. Imaginemos que um ciclista surge na calçada onde Pedro caminha e que, nesse momento, Pedro se lembra de que lhe falta pão e atravessa a rua a fim de ir à padaria. A chegada do ciclista constitui um perigo, e Pedro modificou sua atividade. Mas não diremos que Pedro foi prudente, mesmo que ele tenha deixado um lugar perigoso. Para falar de prudência, é preciso que Pedro tenha deixado um lugar por causa do perigo representado pela bicicleta - e não por causa da sua necessidade de comprar pão. O enunciado Pedro foi prudente não significa uma simples junção de características, mas uma argumentação. Pedro foi prudente evoca a argumentação (8):

(8) Pedro encontrou um perigo e, portanto, modificou sua atividade.
Mudemos o sujeito gramatical e o tempo verbal. O enunciado Maria é prudente evoca (9):

(9) Se Maria encontrar um perigo, ela modificará sua atividade.

(8) e (9) são, ambos, construídos sobre um mesmo esquema, um mesmo esqueleto, independentemente do tempo gramatical, da diferença entre portanto e se, dos nomes próprios Pedro e Maria. A TBS anota esse esquema PERIGO DC MODIFICAR e fala de "aspecto argumentativo". O DC lembra que os encadeamentos (8) e (9) comportam uma conjunção do tipo de donc . A TBS prevê paráfrases de Pedro foi prudente e de Maria é prudente por (8) e (9), inscrevendo o esquema PERIGO DC MODIFICAR na significação de prudente.

Inversamente, os enunciados Pedro foi imprudente e Maria é imprudente evocam os encadeamentos (8') e (9'):

(8') Pedro encontrou um perigo, no entanto não modificou sua atividade.

(9') Até mesmo se Maria encontrar um perigo, ela não modificará sua atividade.

Esses encadeamentos são, novamente, construídos sobre um mesmo esquema, desta vez anotado PERIGO PT NEG MODIFICAR. O PT lembra que os encadeamentos (8') e (9') comportam uma conjunção do tipo pourtant . O aspecto PERIGO DC MODIFICAR é chamado "normativo" e o aspecto PERIGO PT NEG MODIFICAR é qualificado como "transgressivo". Dos dois aspectos, apenas o aspecto normativo PERIGO DC MODIFICAR está inscrito na significação de prudente. $\mathrm{O}$ aspecto transgressivo PERIGO PT NEG MODIFICAR pertence à significação de imprudente. Ele não pertence à significação de prudente, pois nenhum enunciado de Pedro foi prudente evoca (8').

A significação de prudente está constituída por certos e apenas certos esquemas argumentativos. Ela contém PERIGO DC MODIFICAR e não contém 
PERIGO PT NEG MODIFICAR. Contudo, ela não é reduzida ao aspecto PERIGO DC MODIFICAR. Ela contém outros esquemas argumentativos, particularmente esquemas de um tipo um pouco diferente dos aspectos. São esquemas argumentativos mais gerais e, ao mesmo tempo, menos precisos: o que chamo de quase-blocos. Veremos que a significação de prudente contém o quase-bloco PRUDENTE(SEGURANÇA).

Imaginemos que Maria precise dirigir seu carro à noite, na neve, por uma pequena estrada montanhosa. O emprego de Maria é prudente em (10) evoca o encadeamento argumentativo (11):

(10) É verdade que é um pouco perigoso, mas Maria é prudente.

(11) Maria é prudente, portanto estará segura.

(11) concretiza o aspecto PRUDENTE DC SEGURANÇA, que está, como PERIGO DC MODIFICAR, previsto na significação de prudente. Contudo, contrariamente a PERIGO DC MODIFICAR, o aspecto PRUDENTE DC SEGURANÇA não está inscrito tal qual na significação de prudente. Ele está somente "previsto", já que ele não é mobilizado o tempo todo. Alguns empregos da frase Maria é prudente evocam (11), mas esse não é o caso de todos os empregos dessa frase e, assim, (12) evoca (13):

(12) Maria é prudente, mas é muito perigoso.

(13) Ainda que ela seja prudente, Maria não estará em segurança.

Ao lado do esquema PRUDENTE DC SEGURANÇA, a significação de prudente "prevê" igualmente 0 esquema PRUDENTE PT NEG SEGURANÇA concretizado por (13). A significação de prudente contém a possibilidade dos dois aspectos. Ela contém sua alternativa sem conter, diretamente, os dois aspectos. A significação de prudente contém 0 que compartilham os dois aspectos PRUDENTE DC SEGURANÇA e PRUDENTE PT NEG SEGURANÇA. É esse núcleo comum aos dois aspectos que eu qualifico como "quase-bloco". Eu anoto PRUDENTE(SEGURANÇA), colocando entre parênteses o termo SEGURANÇA, que se especifica em ...DC SEGURANÇA no aspecto normativo PERIGO DC SEGURANÇA e que se especifica em ...PT NEG SEGURANÇA no aspecto transgressivo PERIGO PT NEG SEGURANÇA. A significação de prudente contém 0 quase-bloco PRUDENTE(SEGURANÇA). Alguns empregos de prudente, como os exemplos (10) e (12) que acabamos de estudar, especificam sob qual aspecto o quase-bloco foi expresso. Mas esse não é sempre o caso, já que, às vezes, somente o quase-bloco é expresso, como no pequeno texto que segue - os resumos dos filmes nos programas televisivos têm, frequentemente, essa forma:

(14) Pedro e Maria partem de férias para a montanha. Durante um passeio, Pedro se machuca. Maria parte sozinha à procura de socorro. A noite chega, ouvem-se lobos. Maria é prudente, mas isso será suficiente?

(14) exprime 0 quase-bloco PRUDENTE(SEGURANÇA) e o locutor joga com a imprecisão do quase-bloco. Maria estará portanto em segurança? Ou, mesmo assim, Maria terá problemas?

A palavra sabre pode ser estudada da mesma maneira. Como a significação de prudente, a de sabre é reduzida a esquemas argumentativos, de modo que esse termo não é mais descritivo do que a palavra prudente.

Começaremos, assim, apontando que um sabre, sendo uma arma, no enunciado Pedro tem um sabre, evoca a argumentação (15):

(15) Até mesmo se encontrar alguém forte, Pedro poderá feri-lo.

A significação de sabre contém o esquema FORTE PT FERÍVEL de (15) e esse esquema é novamente concretizado pelo encadeamento 
argumentativo (16), evocado por nosso primeiro exemplo (1):

(1) O pirata empunhou um sabre com o qual se lançou sobre o tenente do Rei.

(16) Até mesmo se o tenente do Rei fosse forte, o pirata poderia feri-lo.

Contudo, o encadeamento argumentativo (16) não é suficiente para parafrasear o enunciado (1); a significação da palavra sabre contém outras indicações que distinguem, por exemplo, esse termo da palavra pistola, e é por meio dessas outras argumentações que (16) é evocado. Quais são essas outras argumentações? Como distinguir os dois nomes de arma que são sabre e pistola? O Trésor de la Langue Française (TLF) ou o Larousse distinguem sabre de pistola juntando à definição de sabre uma descrição física. O TLF utiliza a palavra, aparentemente científica, convexa:

« arma branca, com uma longa lâmina pontuda, levemente convexa do lado cortante, cuja forma e comprimento variam de acordo com a época e com o país"

e a definição do Larousse contradiz precisamente sobre esse ponto aquela do TLF:

"arma branca, reta ou curva, cortante somente em um dos lados".

Não é a aparência física que faz a definição de sabre. É na função dos sabres que é preciso buscar a definição. Um sabre é uma arma de luta corporal e é o contraste entre (1) e (17) que é característico do que distingue o nome sabre do nome de outras armas, como pistola:

(1) O pirata empunhou um sabre com o qual se lançou sobre o tenente do Rei.

(17) O pirata empunhou uma pistola com a qual se lançou sobre o tenente do Rei.
A significação de sabre contém o aspecto NEG CONTATO DC NEG EFEITO e (1) evoca (18):

(18) Se o pirata não se aproximasse, ele não feriria o tenente do Rei.

A necessidade de um contato faz parte da própria significação de sabre; é por isso que os dois enunciados de (1), ele empunhou um sabre e com o qual se lançou sobre o tenente do Rei, aparecem como descrevendo a mesma ação. É, ao contrário, o aspecto NEG CONTATO PT EFEITO que pertence à significação de pistola e (17) evoca (19):

(19) Mesmo se o pirata não se aproximasse, ele poderia ferir o tenente do Rei.

Assim como o enunciado (1), o enunciado (17) é possível, mas empunhar uma pistola e se lançar sobre o tenente são compreendidos, desta vez, como descrevendo duas ações distintas.

Essas primeiras observações permitem, igualmente, analisar (2):

(2) Seu sabre estava enferrujado há muito tempo, ele deu-o a seu filho de sete anos.

Poderíamos inicialmente crer que (2) constitui uma objeção à presença de FORTE PT FERÍVEL em sabre: o sabre do pai, contrariamente ao do pirata, não poderá machucar os fortes. Minha resposta é que o adjetivo enferrujado age nesse caso como uma negação. O sabre do pai não é um sabre que, além de tudo, está enferrujado, mas constitui, digamos, um pseudo-sabre. O emprego de sabre em (2) significa, novamente, FORTE PT FERÍVEL, já que esse aspecto foi transformado pelo atributo enferrujado em FORTE DC NEG FERÍVEL. Do mesmo modo que o prefixo negativo $\mathrm{im}$ - diante de prudente transformou PERIGO DC MODIFICAR em PERIGO PT NEG MODIFICAR, o adjetivo enferrujado transforma, nesse caso, FORTE PT FERÍVEL em FORTE DC NEG FERÍVEL. Prevemos, então, que (2) evoca o 
encadeamento (20) - a respeito do pai, já que seu sabre relaciona o sabre ao pai:

(20) Se o pai encontrasse alguém forte, ele não poderia feri-lo.

Entretanto, um ponto ainda resta ser explicado: o desenvolvimento de (2) por ele o deu ao seu filho de sete anos. A possibilidade de introduzir um donc em (2) assinala, inicialmente, que esse discurso, na sua totalidade, constitui um encadeamento argumentativo: ele concretiza o aspecto NÃO UTILIZÁVEL DC DÁ. O pai dá um objeto do qual ele não se serve. Contudo, o pai não se contenta em se desfazer de seu velho sabre. O verbo dar pressupõe que o sabre enferrujado interessa ao filho, certamente não porque está enferrujado, mas porque ainda é um sabre. Um elemento da significação de sabre não foi negado por enferrujado e sempre é significado por (2). Elaborarei a hipótese de que se trata do quasebloco ARMA(PROVOCA MEDO). Notaremos, de fato, que esse quase-bloco é expresso tal qual por (1), sob a forma de quase-bloco:

(1) O pirata empunhou um sabre com o qual se lançou sobre o tenente do Rei

- (1) não nos diz se o tenente tem medo ou não, mas a questão da sua reação está presente. O quasebloco ARMA(PROVOCA MEDO) é igualmente expresso por (2): é ele que torna o sabre desejável aos olhos da criança.

Eu não levarei mais adiante essas análises lexicais. Considerarei simplesmente que a significação da palavra sabre está constituída, da mesma maneira que a significação da palavra prudente, por aspectos argumentativos e por quaseblocos. A palavra sabre não é mais informativa que a palavra prudente. Não há lugar para manter, no interior da significação linguística, traços que permitam prever um potencial informativo das palavras. A significação linguística é totalmente argumentativa.

\section{Aspectos argumentativos, quase-blocos e} blocos semânticos

De modo geral, a TBS defende que a significação de uma palavra contém sempre esquemas argumentativos, aspectos ou quaseblocos, e contém unicamente esquemas argumentativos. Esses esquemas argumentativos não são passíveis de avaliação em termos de verdade ou falsidade. Mesmo que seja possível observar que uma situação é perigosa e que alguém modificou sua atividade, nada permitiria determinar se a pessoa modificou sua atividade por causa do perigo: não podemos perceber se Pedro foi prudente. A significação é totalmente argumentativa e é por isso que a palavra parece - afirmo "parece" - informativa (sabre) ou avaliativa (prudente).

Os aspectos, dois a dois, são previstos por quase-blocos:

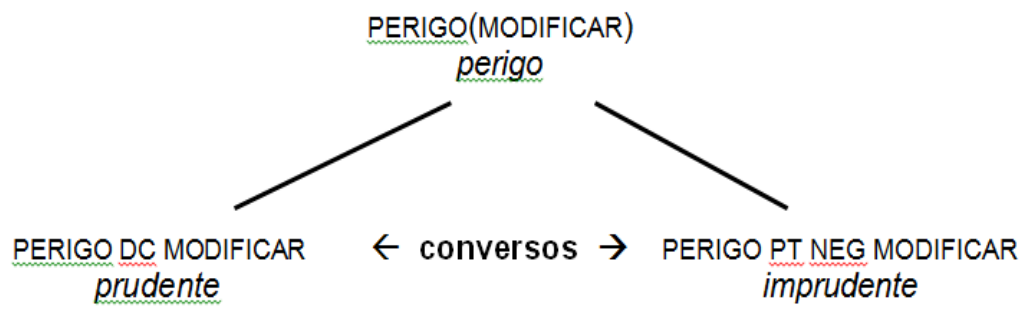

Especificando um único quase-bloco, esses dois aspectos são chamados "conversos" um do outro. O quase-bloco é lexicalizado na palavra perigo e os dois aspectos são, respectivamente, lexicalizados em prudente (PERIGO DC MODIFICAR) e em imprudente (PERIGO PT NEG MODIFICAR): a prudência e a imprudência são duas reações ao perigo.

Do mesmo modo, o quase-bloco NEGPERIGO(NEGMODIFICAR), inscrito na significação de sem perigo, se declina em dois aspectos conversos, um normativo e outro transgressivo: 


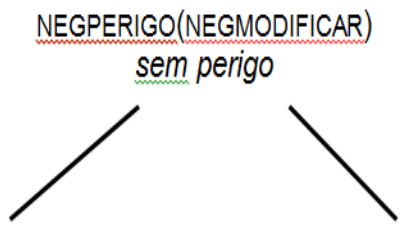

NEGPERIGO DC NEG MODIFICAR $\leftarrow$ conversOS não medroso

$\rightarrow$ NEG PERIGO PT MODIFICAR medroso

Ser medroso (NEG PERIGO PT MOFIFICAR) e não ser medroso (NEG PERIGO DC NEG MODIFICAR) são duas reações à ausência de perigo.

Enfim, os próprios quase-blocos são aparentados. PERIGO(MODIFICAR) e NEGPERIGO(NEGMODIFICAR) compartilham, de fato, uma mesma visão da modificação: modificar sua atividade é, nesse caso, precisamente, tomar precauções - e não apenas, como Pedro indo comprar pão, mudar de ideia. Chamamos "bloco semântico" o núcleo comum aos dois quase-blocos:

\section{Bloco do perigo que modifica o comportamento}
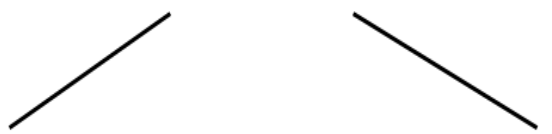

PERIGO(MODIFICAR) $<$ complementares $\rightarrow$ NEGPERIGO(NEGMODIFICAR) perigo sem perigo

Os dois quase-blocos são chamados "complementares" um do outro - mais exatamente, como veremos quando estudarmos o paradoxo, eles são "complementares no interior de um quadrado de transposição". PERIGO(MODIFICAR) está inscrito na significação de perigo, enquanto que NEGPERIGO(NEGMODIFICAR) está inscrito na significação de sem perigo. Núcleo dos quase-blocos, o bloco semântico é igualmente núcleo dos aspectos previstos pelo quase-bloco: prudente, imprudente, medroso são, todos eles, termos que consideram a modificação do comportamento como uma precaução.

Blocos, quase-blocos, aspectos e encadeamentos argumentativos aparecem, assim, como seres linguísticos cada vez mais concretos: os blocos se especificam em quase-blocos, que se especificam em aspectos, que se concretizam em encadeamentos argumentativos. Além disso, presentes na significação, quase-blocos e aspectos estabelecem algumas relações entre as palavras. Relações de modo: porque PERIGO DC MODIFICAR especifica PERIGO(MODIFICAR), ser prudente (PERIGO DC MODIFICAR) é um "modo" de reagir ao perigo (PERIGO(MODIFICAR)). Relações de contradição: porque eles significam os aspectos conversos, ser prudente e ser imprudente são opostos, porque eles significam os quase-blocos complementares, perigo e sem perigo são opostos. E, finalmente, veremos agora, relações graduais abreviei PERIGO por DG e MODIFICAR por MODF a fim de ajustar o diagrama à largura da página:

\section{Quadrado de transposição4}

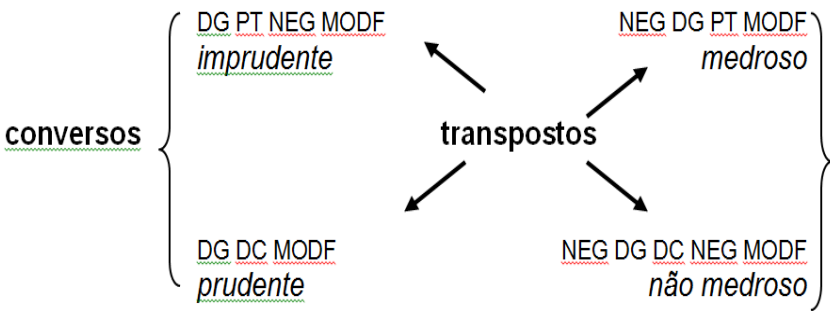

conversos

A coluna da esquerda agrupa os dois aspectos conversos do quase-bloco PERIGO(MODIFICAR) e a coluna da direita agrupa os dois aspectos conversos do quase-bloco complementar NEGPERIGO(NEGMODIFICAR). Em diagonal, os aspectos são chamados "transpostos". Assim como os aspectos conversos, os transpostos especificam o mesmo bloco semântico e são de naturezas diferentes: um é normativo, o outro, transgressivo. Mas, enquanto a conversão reflete uma relação de contradição, a transposição reflete - como eu já anunciava - uma relação gradual, que pode ser expressa por até mesmo: podemos dizer Ele é prudente e até mesmo medroso, enquanto que é impossível afirmar *Ele é medroso e até mesmo prudente; de modo semelhante, podemos dizer Ele não é medroso, ele é até mesmo imprudente, enquanto que é impossível afirmar *Ele é imprudente e até mesmo não é medroso. Encontramos aí uma hipótese fundadora da Teoria da Argumentação na 
Língua de Anscombre e Ducrot. A gradualidade organiza o sistema da língua da mesma forma que as relações de contradição banalmente utilizadas pelos lógicos, da mesma forma que as relações de modo funcionam nas classificações aristotélicas em gênero e espécie.

A significação argumentativa das palavras tem, portanto, dois papéis. De um lado, ela permite prever o sentido dos enunciados, ou seja, suas paráfrases, por encadeamentos argumentativos: é a função, lembramos, que Ducrot atribui à significação. Mas, por outro lado, a significação descreve as relações que as palavras mantêm entre si, relações graduais (aspectos transpostos), relações de contradição (aspectos conversos e quase-blocos complementares), relações de modo (aspecto e quase-bloco): reconheceremos, nesse caso, a função que Benveniste atribui à significação. A TBS, construída na perspectiva de Ducrot, não se opõe totalmente ao ponto de vista de Benveniste. Eu admito, de acordo com Benveniste e com todos os estruturalistas, que a significação de uma palavra fora de emprego tem por papel situá-la frente a outras palavras. O ponto em que a TBS se distingue da abordagem de Benveniste é, fundamentalmente, a respeito da noção de sentido. Benveniste admite, de fato, que o sentido dos enunciados descreve sua relação com o mundo, de modo que o sentido não pode ser deduzido da significação estrutural das palavras. A semântica está desvinculada da semiótica. A TBS, ao contrário, admite que o sentido de um enunciado é constituído por uma família de encadeamentos argumentativos que colocam esse enunciado em relação com outros enunciados. Não há, segundo o que penso, nenhum salto da significação das palavras para 0 sentido dos enunciados. As palavras referem-se umas às outras no sistema da língua e o sentido e nossos textos não é nada mais do que um entrelaçamento de encadeamentos argumentativos que se reforçam, se contradizem, ou se generalizam.

Isso significa que os textos só refletem a língua? Significa que as obras de Flaubert, Borges,
Virginia Woolf apenas iluminam uma região dos sistemas já constituídos das suas respectivas línguas? Evidentemente, não é isso que defendo. A criatividade linguística é possível. Certamente, a significação das palavras é capaz de conferir aos textos sua estrutura, mas o entrelaçamento sintático e textual das palavras pode, igualmente, participar dessa estruturação. Ele também é capaz de criar relações entre as palavras e de exprimir com elas esquemas argumentativos. $\mathrm{O}$ entrelaçamento é criativo, e isso tanto mais que as relações que ele instaura entre as palavras ou os esquemas que ele permite exprimir só são, frequentemente, instauráveis e exprimíveis por seu intermédio. Os textos enriquecem o sentido já construído pelas palavras. É isso que nós veremos com o exemplo da "decalagem" e do "paradoxo". A decalagem é uma relação instaurada pelo entrelaçamento das palavras; já o paradoxo decorre de quase-blocos textualmente construídos. Ambos constituem o fato de um locutor que se apropria da língua.

\section{A decalagem}

Qual é o papel do termo a menina na construção do sentido A menina foi prudente? Qual é o papel do verbo chorar em por sensibilidade, Pedro chorou durante a cerimônia? Não são eles que exprimem os esquemas dos encadeamentos evocados pelos dois enunciados: são os termos prudente e sensibilidade que desempenham esse papel. Os empregos de a menina e de chorar servem apenas para construir os encadeamentos. $\mathrm{Na}$ verdade, veremos que é preciso distinguir esses dois casos. O emprego de a menina é muito anedótico, mas o emprego de chorar enriquece o sentido do enunciado no qual aparece.

Voltemos ao exemplo de a menina foi prudente. Imaginemos um pai contanto à sua esposa o passeio que fez com sua filha Maria:

(21) Voltando pra casa, nós paramos em um semáforo. Uma menina, com grandes fones de 
ouvido, chegou correndo. Do outro lado da rua, alguém Ihe fez um sinal. Ela iria atravessar de qualquer modo, mas, por fim, a menina foi prudente. Esse foi um bom exemplo para Maria.

A palavra prudente exprime o esquema PERIGO DC MODIFICAR e o enunciado (21) evoca $\left(21^{\prime}\right)$ :

(21') Havia perigo, portanto a menina modificou seu comportamento.

A significação da palavra prudente prevê o sentido de (21). Ela prevê o sentido de (21), mas não prevê, evidentemente, o emprego de a menina como sujeito gramatical de (21). Ela não prevê a concretização de PERIGO DC MODIFICAR pelo sujeito gramatical a menina e não prevê, consequentemente, o encadeamento (21') em todos os seus detalhes. Se o esqueleto do encadeamento é imposto pela significação da palavra prudente, o próprio encadeamento decorre, do mesmo modo, do emprego de a menina. Ele depende do emprego de a menina sem, contudo, depender - e este é o ponto importante - da significação de a menina. Como já vimos com o exemplo (3), em que Pedro esperava João em uma sala de esgrima, alguns empregos das palavras (sabre, em (3); a menina, em (21)) servem somente para concretizar o aspecto no discurso. Digo que o emprego de a menina em (21) é "singularizante" e, por contraste, digo que o emprego de prudente é "construtivo". A intervenção de a menina em (21) não produz nenhum enriquecimento textual; o entrelaçamento de a menina e de prudente não faz ressoar juntas as significações dessas duas palavras; o entrelaçamento é puramente material. Mas esse não sempre é o caso.

Agora, comparemos os enunciados (22) e (23):

(22) Pedro deu prova de sensibilidade.

(23) Por sensibilidade, Pedro chorou durante a cerimônia.
Em ambos os casos, a palavra sensibilidade expressa sua significação. Ela comunica 0 aspecto $X$ É COMOVENTE DC Y FICOU EMOCIONADO POR CAUSA DE X e Pedro é descrito, tanto em (23) quanto em (22), como tendo se emocionado por causa de um acontecimento comovente. O emprego de sensibilidade em (23) e em (22) é « construtivo ». Ele exprime a natureza geral do evento que aconteceu. Não há, nesse nível, nenhuma diferença entre (23) e (22). Tanto em um caso quanto em outro, Pedro é descrito como tendo sido sensível.

A diferença entre (23) e (22) está nos detalhes apresentados. (22) não nos diz nada sobre o que foi comovente nem como Pedro ficou emocionado, de modo que (22) evoca o encadeamento (22'), no qual os termos comovente e emocionado são os que já se encontram na estrutura $X$ É COMOVENTE DC $Y$ FICOU EMOCIONADO POR CAUSA DE X:

(22') A situação era comovente, portanto, Pedro ficou emocionado.

O enunciado Pedro deu prova de sensibilidade não traz precisão quanto ao modo pelo qual Pedro provou sua sensibilidade. (22) evoca um encadeamento cuja possibilidade está inscrita na própria significação de sensibilidade.

Tal funcionamento não é o mesmo para o enunciado (23), o qual precisa que a emoção de Pedro se traduziu em lágrimas. Para marcar essa diferença, direi que (23) evoca (23'):

(23') A cerimônia foi comovente, portanto Pedro chorou

Como em (22'), encontramos em (23') a palavra comovente da estrutura X É COMOVENTE DC Y FICOU EMOCIONADO POR CAUSA DE X. Ao contrário, não encontramos mais estar comovido, que é, aqui, substituído por chorar. Há uma "decalagem" entre o encadeamento (23') e o esquema X É COMOVENTE DC Y FICOU EMOCIONADO POR CAUSA DE $X$ devido ao verbo chorar, que ilustra a emoção de Pedro. Digo que o emprego do verbo 
chorar em (23) é "caracterizante". O enunciado (22) não comportava o termo caracterizante de modo que (22') era apenas um reflexo de X É COMOVENTE DC $Y$ FICOU EMOCIONADO POR CAUSA DE X. O enunciado (23) comporta, em contrapartida, o termo caracterizante chorar, de modo que (23') não é um simples reflexo discursivo da significação de sensibilidade. Há decalagem.

Pensar-se-á, talvez, que o encadeamento (23') é tão banal quanto 0 encadeamento (22'). Certamente, o nome sensibilidade não impõe a ideia de que Pedro chorou, mas o verbo chorar é, pela própria língua, classificado como um modo de ficar emocionado. Por que distinguir o papel de chorar em (23) daquele de a menina em (21)? Por que não afirmar que ambos são singularizantes? Minha resposta é que o emprego de a menina em (21) se limita a construir o encadeamento (21') enquanto que o emprego de chorar em (23), por sua vez, constrói (23') e compara chorar e comovido. A comparação, eu admito, não é aqui produtora de sentido, mas se torna produtora em um exemplo como (24):

(24) Por sensibilidade, Pedro comeu muito durante a cerimônia

(24') A cerimônia foi comovente, portanto Pedro comeu muito

De fato, comer não é classificado pela língua dentre os modos de ficar emocionado, de modo que o emprego de comer produz aqui um efeito de sentido que a menina não produz em (21).

Para tornar evidente a decalagem, modificarei um pouco a descrição do sentido dos enunciados e associarei a eles não simplesmente encadeamentos, mas encadeamentos relacionados a aspectos. Dessa forma, direi que (24) evoca:

(24') A cerimônia foi comovente, portanto Pedro comeu muito entendido como concretizando $\mathrm{X}$ É COMOVENTE DC Y FICOU EMOCIONADO POR CAUSA DE X.

Da mesma forma, direi que (23) Por sensibilidade, Pedro chorou durante a cerimônia evoca:

(23') A cerimônia era comovente, portanto Pedro chorou

entendido como concretizando $\mathrm{X}$ É COMOVENTE DC Y FICOU EMOCIONADO POR CAUSA DE X.

Direi, ainda, que (22) Pedro deu uma prova de sensibilidade evoca:

(22') A situação era comovente, portanto Pedro se emocionou

entendida como concretizando $X \quad E ́$ COMOVENTE DC Y FICOU EMOCIONADO POR CAUSA DE X.

Graças aos seus termos caracterizantes comer e chorar, os sentidos de (24) e (23) estão decalados; sem termo caracterizante, o sentido de (22) não está decalado. A decalagem compara termos. Essa comparação pode ser banal, como em (23); ela pode ser inesperada, como em (24); pode ser até mesmo absurda, como na réplica irônica de Ardromaque:

Pyrrhus Seu ódio por Hector ainda não acabou.

Eles temem seu filho.

Andromaque (25) Objeto digno de medo! Uma criança infeliz que ainda não sabe que Pyrrhus é seu mestre e que é filho de Hector.

Essa passagem foi extraída da peça de Racine Andromaque (ato I, cena 4). Lembremos o contexto. Ao fim da guerra de Tróia, o guerreiro grego Pyrrhus recebeu como troféu Andromaque, a viúva de Hector, bem como seu filho, Astyanax. Quando a peça 
começa, os gregos pedem a Pyrrhus que lhes entregue Astyanax, de quem eles temem vingança. Pyrrhus hesita, pois ele ama Andromaque e espera, apesar de suas atuais recusas, convencê-la a casarse com ele. Na cena da qual foi extraído o trecho, Pyrrhus anuncia à Andromaque a embaixada dos Gregos.

A réplica de Pyrrhus não é irônica. Seu último enunciado, de número (26), abaixo, é parafraseável por (26'):

(26) Eles temem seu filho.

(26') Astyanax é o filho de Hector, de quem eles têm medo, tido como concretizando AMEAÇADOR DC TEMIDO

O verbo temer é constitutivo e exprime AMEAÇADOR DC TEMIDO; quanto ao emprego do termo complexo seu filho, eu o interpretei aqui como caracterizante. Astyanax é ameaçador pelo fato de ser filho de Hector. Essa decalagem é bem compreendida. $O$ início do discurso de Pyrrhus lembrava, na verdade, que Hector era inimigo dos Gregos; o filho de um inimigo constitui uma ameaça. A decalagem é banal, (26) não é irônico.

Consideremos, agora, a réplica (25) de Andromaque. Ela está constituída por duas frases gramaticais: uma exclamação (Objeto digno de medo!) e uma frase constituída unicamente por um grupo nominal (uma criança infeliz...). A exclamação determina o aspecto AMEAÇADOR DC TEMIDO. O termo constitutivo medo significa o quase-bloco (AMEAÇADOR)TEMIDO, núcleo comum de AMEAÇADOR DC TEMIDO e NEG AMEAÇADOR PT TEMIDO, e o operador digno especifica esse quasebloco sob o aspecto normativo AMEAÇADOR DC TEMIDO. Através de sua exclamação, Andromaque reformula o mesmo aspecto que Pyrrhus. Ela retoma novamente Astyanax através da propriedade argumentativa AMEAÇADOR DC TEMIDO. Mas sua réplica não se encerra aí. Esse aspecto expresso, Andromaque o precisa, é concretizado graças à frase nominal. Ora, onde Pyrrhus empregava o termo filho de Hector, Andromaque utiliza, por sua vez, criança infeliz. É criança infeliz que agora desempenha o papel de termo caracterizante e Andromaque evoca:

(25’) Astyanax é uma criança infeliz, portanto os gregos o temem compreendido como concretizando AMEAÇADOR DC TEMIDO

Como o conteúdo (26’) da réplica de Pyrrhus, o conteúdo (25’) da réplica de Andromaque está decalado. Mas, assim como a decalagem construída por Pyrrhus é compreendida (o filho de um inimigo constitui uma ameaça), a decalagem construída por Andromaque é absurda: uma criança infeliz não constitui uma ameaça; a desventura de uma criança não manifesta seu caráter ameaçador. A decalagem é absurda, o conteúdo argumentativo é impossível de ser sustentado, e Andromaque o assume falsamente. Seu enunciado é irônico.

A decalagem constitui, assim, uma das riquezas da língua. Decorrente do entrelaçamento das palavras e não apenas de sua aparição, ela permite que o aspecto seja especificado, detalhado (Por sensibilidade, Pedro chorou é, nesse sentido, mais rico que Pedro deu uma prova de sensibilidade), como ela permite, inversamente, que 0 encadeamento seja generalizado e a natureza do evento, determinada (por sensibilidade, Pedro chorou é igualmente mais rico que Pedro chorou). 0 entrelaçamento das palavras permite instaurar, entre termos, relações que não estavam previamente inscritas na sua significação e, por isso, permite construir textos que não são o simples reflexo do sistema linguístico. A decalagem revela um ponto de vista, ou, mais exatamente, uma apropriação da língua, uma utilização da língua por um locutor que, entrelaçando termos caracterizantes e termos constitutivos, aparece para nós como convencional ou malicioso.

\section{0 paradoxo}

O paradoxo é, igualmente, o fato de um locutor: um locutor que escolhe construir textualmente o esquema argumentativo que concretiza seu enunciado. Comecemos por um exemplo: 
(27) Pedro não será condenado, até mesmo, e sobretudo, se ele é culpado.

(27) evoca os encadeamentos (28) e (29):

(28) Até mesmo se Pedro for culpado, ele não será condenado

(29) Se Pedro for culpado, ele não será condenado

A situação descrita por (28) é estranha, mais estranha que aquela descrita por (30):

(30) Se Pedro é culpado, ele será condenado

Não diremos, no entanto, que (28) é paradoxal, pois o emprego de até mesmo se em (28) assinala precisamente que seria normal que Pedro fosse condenado. Contrapartida transgressiva de (30), (28), de certa forma, "confirma" (30) do mesmo modo que, segundo a sentença do direito latino, a exceção "confirma" a regra (exceptio firmat regulam). A estranheza assinalada - e declarada - por (28) está no mesmo quadro daquela de (30). (30), por sua banalidade, é igualmente doxal, e seu converso transgressivo (28), mesmo que ele seja menos banal que (30), é igualmente doxal. O mesmo não acontece com o encadeamento (29) que, contrariamente a (28), é normativo. (29) não assinala uma estranheza, ao contrário. (29) faz da não condenação de Pedro um caso normal e, ao fazer isso, se opõe à doxa de (30) e faz alusão a comentários sobre a instituição que não condena Pedro: por que ela absolve os culpados? O encadeamento (29) é insólito, paradoxal. Como analisar esse paradoxo?

Poderíamos pensar em recorrer às crenças sociais. Tratar-se-ia de dizer que (28) e (30) repousam sobre a crença banal segundo a qual a culpabilidade leva à punição, enquanto que (29), ao contrário, repousaria sobre a crença inabitual de que a culpabilidade deva ser protegida. (28) e (30) seriam doxais, porque a crença de seus locutores seria compartilhada; já (29) seria paradoxal, porque, inversamente, a crença de seu locutor não seria compartilhada. Entretanto, uma análise como essa é insatisfatória, pois nada no encadeamento (29) nos diz que o próprio locutor crê que a culpabilidade deva ser protegida. O que o locutor de (29) nos diz é apenas como Pedro será tratado pela instituição: o aspecto FALTA DC NEG PUNIÇÃO que esquematiza (29) não é uma crença do locutor, mas uma propriedade que o locutor utiliza para descrever o futuro de Pedro. O mesmo pode ser dito de (30) e de (28). Seus esquemas FALTA DC PUNIÇÃO e FALTA PT NEG PUNIÇÃO não se tratam de crenças. (28) e (30) são, como (29), descrições de Pedro, e seu caráter doxal não diz respeito a uma crença que seus locutores mobilizariam. Doxa e paradoxo são fenômenos interiores à língua. A banalidade de (30) não diz respeito a uma banalidade de crenças que esse encadeamento trairia, mas à sua banalidade linguística, à sua conformidade com a língua.

Mas em que sentido há conformidade com a língua? Porque, inversamente, o paradoxo não é contrário à língua. Não apenas os encadeamentos paradoxais são possíveis como seus próprios aspectos são, às vezes, lexicalizados. Não somente é possível dizer (31):

(31) Isso fez Pedro sofrer muito e, por conseguinte, ele sentiu certo prazer

mas, além disso, o próprio esquema concretizado por (31), SOFRIMENTO DC PRAZER, pertence à significação da palavra masoquista ((31) poderia ser resumido por Pedro foi masoquista). A língua aceita e integra o paradoxo em seu próprio léxico. O paradoxo não é contrário à língua. Nós veremos que, se certos aspectos argumentativos paradoxais são efetivamente lexicalizados, o mesmo não acontece com os quase-blocos dos quais eles provêm. É no nível dos quase-blocos que se define a conformidade, ou, ao contrário, a oposição à língua que constituem a doxa e o paradoxo; é por herança que aspectos e encadeamentos são, por sua vez, doxais ou paradoxais. 
Dessa forma, direi que um quase-bloco é "doxal" se ele pertence à significação linguística de uma palavra da língua. Pertencendo à significação de falta - ou de culpado $\neg$ - , o quase-bloco FALTA(PUNIÇÃO) é, por conseguinte, doxal. Direi, em seguida, que um aspecto é "doxal" se ele especifica um quase-bloco doxal e que um encadeamento é "doxal" se ele concretiza um aspecto doxal. Nessa medida, os aspectos FALTA DC PUNIÇÃO e FALTA PT NEG PUNIÇÃO são doxais, assim como os encadeamentos argumentativos (30) e (28) que os concretizam. Essa definição por herança - nós a assinalamos - torna inevitável que o encadeamento transgressivo (28) tenha a mesma doxalidade que o encadeamento normativo (30). Desde que um quase-bloco seja doxal, todos os encadeamentos que ele prevê, transgressivos ou normativos, são doxais. A conformidade se dá tanto com no entanto quanto com portanto.

O mesmo ocorre com o paradoxo? Nós avançamos, pois, se SOFRIMENTO DC PRAZER está lexicalizado em masoquista, o quase-bloco SOFRIMENTO(PRAZER), ao contrário, não está: a significação de sofrimento não contém SOFRIMENTO(PRAZER) Nossa definição permite, portanto, dizer que o encadeamento (31), a respeito do masoquismo de Pedro, não é doxal. Certamente, seu aspecto está lexicalizado, mas não o quase-bloco do qual ele provém. Como a conformidade à língua é julgada no nível dos quase-blocos, (31) não é doxal. O mesmo acontece com o exemplo (29), tomado como ponto de partida:

(29) Se Pedro for culpado, ele não será condenado

O quase-bloco FALTA(NEGPUNIÇÃO) não está lexicalizado, de modo que os ASPECTOS FALTA DC NEG PUNIÇÃO e FALTA PT PUNIÇÃO que ele prevê, bem como o encadeamento (29) que concretiza FALTA DC NEG PUNIÇÃO, não são doxais.

Infelizmente, um problema permanece. Os encadeamentos paradoxais são certamente encadeamentos que não são doxais. Mas essa observação não é suficiente para caracterizar os paradoxais, pois, entre os encadeamentos não doxais, no sentido que acabo de dar para a doxalidade, há também (32):

(32) Meu gato miou, portanto o disco parou

$\mathrm{Na}$ verdade, seu aspecto MIAR DC FAZER PARAR AS MÁQUINAS especifica um quase-bloco MIAR(FAZER PARAR AS MÁQUINAS) que não está lexicalizado. (32) não é, portanto, doxal. Entretanto, ele também não é paradoxal, pois ele não se opõe a nenhum encadeamento doxal. (32) não se opõe a nenhuma doxa. Em particular, se inserirmos não em seu segundo segmento, o encadeamento resultante meu gato miou, portanto o disco não parou não é mais doxal que (32); seu quase-bloco MIAR(NEG FAZER PARAR AS MÁQUINAS) não é mais lexicalizado do que o quase-bloco MIAR(FAZER PARAR AS MÁQUINAS) de (32). Dito de outra forma, até aqui nós temos bem definidos os encadeamentos doxais, mas o conjunto dos encadeamentos não doxais ainda é uma grande desordem que contém tanto encadeamentos inverossímeis, como (32), quanto encadeamentos contrários à doxa, como (29) ou (31). É necessário, ainda, fazer a triagem entre os encadeamentos não doxais. Temos de distinguir os encadeamentos "paradoxais", como (29) e (31), dos encadeamentos simplesmente "contextuais", como (32). O paradoxo não é somente "diferente" da doxa: ele se opõe à doxa, ou, mais exatamente, ele a deforma.

A oposição do paradoxo à doxa aparece nitidamente quando 0 aspecto paradoxal está lexicalizado. Consideremos, novamente, o paradoxal (31), o qual vimos que estava previsto pela palavra masoquista, e o comparemos ao doxal (33):

(31) Isso fez Pedro sofrer muito e, por conseguinte, ele sentiu certo prazer

(33) Isso fez Pedro sofrer muito e, por isso, ele não estava bem 
(31) pode ser um exemplo de Pedro é masoquista, enquanto que (33) significa, ao contrário, Pedro não é masoquista; há entre (31) e (33) a mesma relação que existe entre uma afirmação e sua negação pelo uso de não; nesse sentido, o paradoxo se opõe à doxa. Entretanto, Ducrot e eu demos importância demasiada a essa oposição e erramos ao concebermos o paradoxo como o contrário da doxa, como relacionado a um bloco semântico de certo modo simétrico ao bloco doxal, como o avesso de um bloco doxal. Uma abordagem como essa é simplificadora, pois, se o paradoxal (31) se opõe ao doxal (33), o paradoxal (31), ao contrário, está em relação gradual com o doxal (34):

(34) Isso fez Pedro sofrer muito, no entanto ele não estava tão mal

Na verdade, (34) é um exemplo de Pedro não é sensível e essa formulação de (34) está relacionada por até mesmo à reformulação de (31) por masoquista:

(35) Pedro não é sensível, ele é até mesmo masoquista

Os aspectos SOFRIMENTO PT PRAZER e SOFRIMENTO DC PRAZER estão em relação gradual. O mesmo se dá com o exemplo tomado como ponto de partida. O emprego de sobretudo em (27) marca igualmente a compatibilidade do doxal (28) e do paradoxal (29), bem como sua relação gradual:

(27) Pedro não será condenado, até mesmo e sobretudo - se ele é culpado

(28) Até mesmo se Pedro for culpado, ele não será condenado.

(29) Se Pedro for culpado, ele não será condenado

Certamente opostos, doxa e paraxoxo são compatíveis em um mesmo discurso. É o que mostra ainda o exemplo seguinte, retirado da adaptação francesa que André Maurois fez, em Os silêncios do Coronel Bramble (Les silences du Colonnel Bramble), para o poema Se (If), de Rudyard Kipling:

Se tu podes ser duro sem nunca ficar com raiva

Se tu podes ser bravo e nunca imprudente

Se tu sabes ser bom, se tu sabes ser sábio

Sem ser moral nem pedante

[...] Então os Reis, os Deuses, a Sorte e a Vitória

Serão para sempre teus escravos submissos,

$\mathrm{E}$, o que vale mais do que os Reis e a Glória,

Tu serás um homem, meu filho.

O locutor da estrofe em se adverte seu interlocutor contra um excesso: ele o aconselha a ser duro sem ir até o excesso, que seria a raiva; ele o aconselha a ser bravo sem ir até o excesso, que seria a imprudência; a ser sábio sem que cometa 0 excesso de ser pedante. O locutor instaura uma relação gradual entre duro e com raiva, entre bravo e imprudente, entre sábio e pedante: ele instaura uma relação gradual entre os aspectos significados. Ora, concentremo-nos no exemplo de duro e de com raiva. $O$ adjetivo duro significa o aspecto A FAZ SOFRER PT X FAZ A: trata-se de um aspecto doxal, pois A FAZ SOFRER(NEG X FAZ A) pertence à significação de fazer sofrer. A significação de duro é, ao mesmo tempo, transgressiva e doxal. E quanto ao termo com raiva? Começaremos assinalando que o excesso do qual nos adverte o locutor do verso Se tu sabes ser duro sem nunca ficar com raiva decorre do fato de que em com raiva se encontra a ideia de agir porque causa sofrimento. O locutor aconselha ser duro, de passar além da dificuldade que o faz sofrer, mas ele adverte que não faça sofrer voluntariamente. O verso é comparável à Se tu podes ser duro sem nunca ser cruel, sem nunca ser sádico. A expressão com raiva significa A FAZ SOFRER DC X FAZ A. Ora, esse aspecto é paradoxal. A expressão com raiva (A FAZ SOFRER DC X FAZ A) está em relação de oposição com o aspecto doxal de compassivo (A FAZ SOFRER 
DC NEG X FAZ A) e, ao mesmo tempo - é o que nos mostra o verso de Maurois -, o aspecto paradoxal de com raiva está em relação gradual com o aspecto doxal de duro (A FAZ SOFRER PT X FAZ A). Eu represento essa dupla relação de oposição e de gradualidade entre paradoxo e doxa pelo diagrama seguinte - por razões de espaço, abreviei "A faz sofrer" por "sofrer" e "x faz A" por "fazer":

\section{Quadrado de inversão}

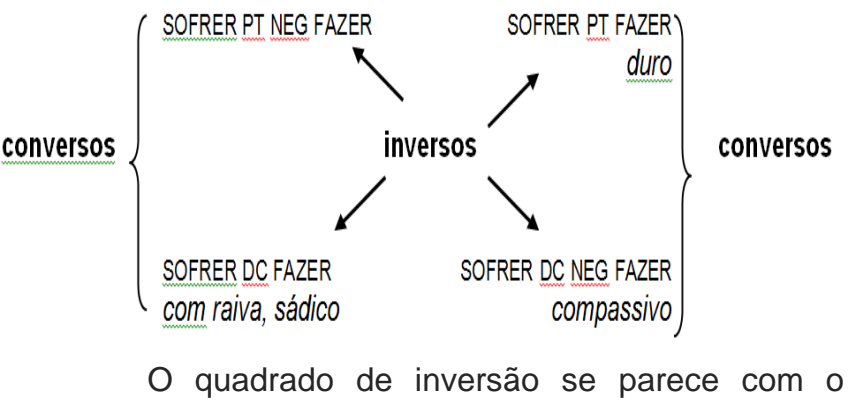
quadrado de transposição que nós vimos a respeito do perigo que modifica o comportamento - e que eu transcrevo logo abaixo - na medida em que ambos comparam quase-blocos conversos, representados em colunas nos diagramas:

\section{Quadrado de inversão}

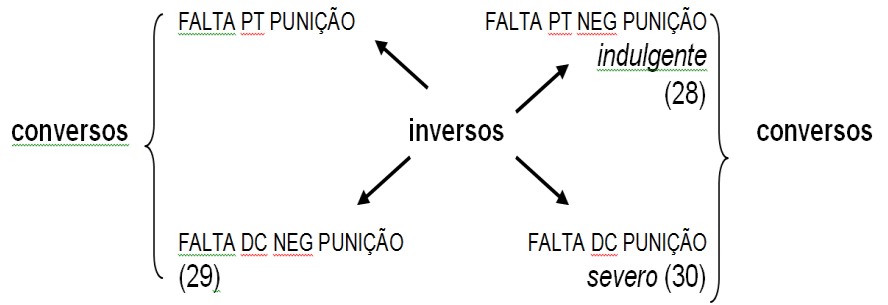

Mas a relação gradual que se instaura entre aspectos em diagonal não é a mesma. No caso da transposição, os primeiros segmentos dos aspectos em relação gradual (DG e NEG DG) se opõem; no caso da inversão, os aspectos em relação gradual compartilham os dois mesmos segmentos (SOFRIMENTO e NEG FAZER). Assim, os quaseblocos comparados não são de mesma natureza. No interior do quadrado de transposição, trata-se de quase-blocos doxais; no caso do quadrado de inversão, trata-se de um quase-bloco paradoxal e de um quase-bloco doxal. A coluna da esquerda representa 0 quase-bloco paradoxal SOFRIMENTO(FAZER) e a coluna da direita representa 0 quase-bloco doxal SOFRIMENTO(NEGFAZER). Esses quase-blocos estão, por sua vez, em relação de oposição (pois há oposição entre seus aspectos normativos) e em relação gradual (pois há gradualidade entre os aspectos inversos).

Digo que eles são "complementares" no interior de um quadrado de inversão. Voltemos ao quadrado de inversão para o exemplo tomado como ponto de partida:

\section{Quadrado de transposição}

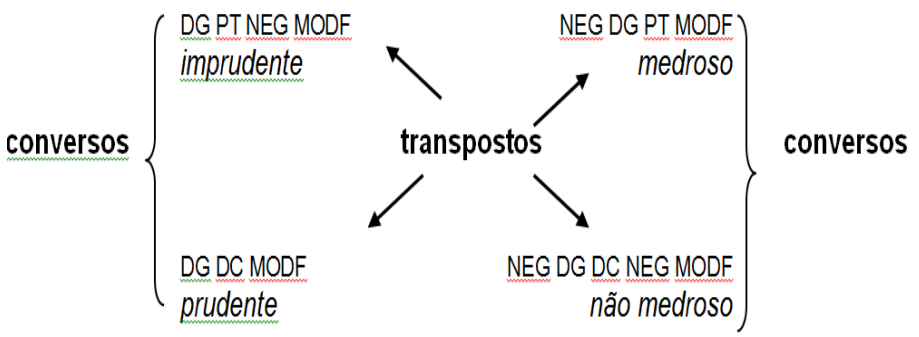

É no nível dos quase-blocos que se definem a doxa e o paradoxo. Um quase-bloco é doxal se ele está lexicalizado e um quase-bloco é paradoxal se seu complementar no interior de um quadrado de inversão é doxal. Portanto, é por herança que aspectos e encadeamentos são doxais e paradoxais. O paradoxo não é simplesmente oposto à doxa: ele é dela uma deformação.

Dessa forma, ao comportar um léxico que prevê encadeamentos e uma gramática que permite construí-los materialmente, a língua define a doxa e torna possível o paradoxo. Essa alternativa é, para mim, reveladora da própria natureza dos nossos discursos, às vezes em conformidade com o léxico, às vezes lugares da invenção. Às vezes, o emprego das palavras torna simplesmente presentes os quaseblocos e os aspectos já ligados a eles: isoladamente, as palavras exprimem sua significação e seu emprego torna reais as virtualidades argumentativas que eles já continham previamente, sem que nenhuma relação nova seja realizada. Entretanto, esse não é sempre o caso. Algumas vezes, o entrelaçamento das palavras cria um novo sentido. Assim, em lugar de expressar sua significação isoladamente, em lugar de impor as potencialidades que a língua ligou a elas, as palavras se combinam, se conectam para construir e manifestar novos esquemas. É uma construção dessa natureza que o 
encadeamento Se Pedro for culpado, ele não será condenado realiza; é dessa maneira que esse enunciado comunica FALTA DC NEG PUNIÇÃO e também FALTA(NEGPUNIÇÃO). Por conexão, ele exprime um aspecto que não se encontra na significação de nenhuma de suas palavras. É o entrelaçamento que ele constrói que produz, diretamente, nesse caso, o sentido. A construção argumentativa que um texto reflete, a montagem que ele mostra, o todo que ele constitui, pode decorrer da significação das palavras, mas pode, igualmente, ser o fato de um locutor que, ao se apropriar da língua, constrói o texto.

\section{Conclusão}

A nova versão da Teoria dos Blocos Semânticos que acabo de apresentar repousa essencialmente sobre uma nova noção: a de quasebloco. Os quase-blocos constituem um grau intermediário entre os aspectos argumentativos e os blocos semânticos. Comuns a dois aspectos argumentativos, eles representam uma alternativa desses aspectos. Presentes na significação das palavras do mesmo modo que os aspectos, eles permitem distinguir, nesta última, duas partes: aquela constituída por aspectos (ela corresponde ao que chamava argumentação interna a uma palavra) e aquela constituída por quase-blocos (ela corresponde ao que eu chamava argumentação externa a uma palavra). De naturezas diferentes, aspectos e quaseblocos se negam de maneiras diferentes: o oposto de um aspecto é seu converso, o oposto de um quasebloco é seu complementar (a versão standard da teoria admitia, sem explicação, que a negação se efetuava de maneiras diferentes se 0 aspecto pertencesse à argumentação interna ou à argumentação externa). A noção de quase-bloco permite, além disso, introduzir uma nova relação entre as palavras: ser prudente (PERIGO DC MODIFICAR) é um "modo" de reagir ao perigo (PERIGO(MODIFICAR)); empunhar um sabre (FORTE PT FERÍVEL) é um "modo" de poder ferir
((NEGFORTE)FERÍVEL). Enfim, a noção de quasebloco permite definir a conformidade linguística de alguns de nossos discursos (é doxal um quase-bloco lexicalizado e, por herança, um aspecto ou um encadeamento previsto por um quase-bloco doxal), como ela permite dar conta da dupla relação, por sua vez opositiva e gradual, que o paradoxo mantém com a doxa (um quase-bloco é paradoxal se seu complementar no interior de um quadrado de inversão for doxal).

Além disso, a nova versão da Teoria dos Blocos Semânticos distingue três tipos de emprego das palavras. Elas podem ser constitutivas (elas determinam o aspecto concretizado), elas podem ser singularizantes (anedóticas, elas levam somente a concretizar o esquema argumentativo em discursos), ou, por fim, elas podem ser caracterizantes (elas concretizam o esquema argumentativo e, ao mesmo tempo, se comparam com ele). Parece, então, que a significação de uma palavra não reflete algo que seja comum a todos os seus empregos, mas apenas aquilo que é comum aos seus empregos constitutivos - e, mais precisamente, a aqueles empregos constitutivos que não são conectivos. A significação não é uma restrição ao dizer. Nem uma restrição a dizer tal coisa (um termo singularizante não significa nada), nem uma restrição a apenas dizer tal coisa. No entrelaçamento das palavras, existe uma riqueza de sentido possível. Assim, empregado como caracterizante, um termo pode construir um encadeamento decalado e, dessa forma, reforçar o aspecto concretizado, comparando os encadeamentos que ele prevê com o encadeamento decalado - ele pode reforçar o aspecto ou, por ironia, tornar absurda sua utilização. Do mesmo modo, conectado a uma outra palavra, um termo pode exprimir novos aspectos até deformar a doxa em paradoxo. Se a língua fornece um léxico carregado de encadeamentos pré-construídos, ela fornece, igualmente, uma gramática que permite colocar em relação encadeamentos pré-construídos com novos encadeamentos, bem como construir novos esquemas de encadeamentos. 
A significação das palavras não nos força a desenvolver e a repetir, texto após texto, a estrutura argumentativa da língua. A estrutura que o léxico pode dar a um texto não é a estrutura necessária de todos os textos. A estrutura argumentativa da língua é, antes de tudo, uma norma. Árbitro de todos os nossos discursos, é ela que nos leva a julgar como coerentes os discursos doxais e, inversamente, a julgar absurdos ou paradoxais os outros discursos. É em referência à estrutura do léxico que nós julgamos tal discurso convincente e tal outro não, tal discurso banal e tal outro semanticamente rico. Se somos livres para colocar em funcionamento todas as construções linguísticas, por outro lado a imagem que nós damos de nós mesmos, a solidez de nossos discursos, suas qualidades estilísticas, permanecem submetidas às regras previstas pela significação argumentativa do léxico.

\section{Referências}

ANSCOMBRE, J-Cl. (1989) « Théorie de l'argumentation, topoï et structuration discursive, Revue québécoise de linguistique, n¹8, 13-55.

ANSCOMBRE, J-Cl et O. Ducrot (1983) L'argumentation dans la langue, Liège : Mardaga.

BENVENISTE, E. (1966) Problèmes de linguistique générale, Paris : Gallimard.

CAREL, M. (2011) L'entrelacement argumentatif, Paris : Honoré Champion.

DUCROT, O. (1972) Dire et ne pas dire, Paris : Hermann.

DUCROT, O. (1988/1995) « Topoï et formes topiques ", repris avec quelques remaniements in $\mathrm{J}-\mathrm{Cl}$. Anscombre (ed.) Théorie des topoï, Paris : Kimé, 85-99.

DUCROT, O. et M. Carel (1999) « Les propriétés linguistiques du paradoxe : paradoxe et négation » Langue Française n¹23, 27-40.

\section{COMO CITAR ESSE ARTIGO}

CAREL, Marion. Signification et argumentation. Signo, Santa Cruz do Sul, v. 42, n. 73, jan. 2017. ISSN 19822014. Disponível em: <https://online.unisc.br/seer/index.php/signo/article/view/8579>. Acesso em:_ doi: http://dx.doi.org/10.17058/signo.v42i73.8579. 